\title{
Diet-induced vitamin $D$ deficiency triggers inflammation and DNA damage profile in murine myometrium
}

This article was published in the following Dove Press journal: International Journal of Women's Health

\author{
Heba Elhusseini' \\ Hoda Elkafas ${ }^{1,2}$ \\ Mohamed Abdelaziz ${ }^{3}$ \\ Sunil Halder' \\ Ihor Atabiekov' \\ Noura Eziba' \\ Nahed Ismail ${ }^{4}$ \\ Abdeljabar El Andaloussi' \\ Ayman Al-Hendy' \\ 'Department of Obstetrics and \\ Gynecology, University of Illinois \\ of Chicago, Chicago, IL, USA; \\ 2Pharmacology and Toxicology \\ Department, National Organization \\ for Drug Control and Research, Cairo, \\ Egypt; ${ }^{3}$ Department of Obstetrics \\ and Gynecology, Mansoura University \\ Hospital, Mansoura Faculty of \\ Medicine, Mansoura, Egypt; ${ }^{4} \mathrm{Clinical}$ \\ Microbiology Division, University of \\ Illinois of Chicago, Chicago, IL, USA
}

Correspondence: Abdeljabar El Andaloussi; Ayman Al-Hendy 909, South Wolcott Avenue, 7III College of Medicine Research Building (MC 808), University of Illinois at Chicago, Chicago, IL 606I2, USA

Tel + I 3 I 29965629

Email aelandal@uic.edu;

aalhendy@uic.edu
Background: Previously, we reported a significantly higher prevalence of uterine fibroids (UFs) in African American women. This minority group also commonly suffers from vitamin D deficiency. We have demonstrated that $1,25(\mathrm{OH})_{2} \mathrm{D}_{3}$ attains a fibroid growth inhibitory impact through its ability to block the G1/S (gap 1/synthesis) phase of the cell cycle. Vitamin D is involved in DNA damage as well as in immune response regulation, anti-inflammation, autoimmunity and cancer. Since most of the prior data on vitamin D and UF were generated in vitro via established cell lines, it was necessary to verify and validate this observation in vivo using a diet-induced vitamin D-deficient mouse model.

Materials and Methods: Our model of vitamin D lacking function was established using 8-week exposure of C57/BL6 mice to vitamin D-deficient diet provides evidence of different functions accomplished by vitamin $\mathrm{D}$ in the regulation of myometrium homeostasis disrupted in the context of uterine fibroid.

Results: We found that vitamin D deficiency was associated with increased expression of sex steroid receptors in murine myometrium, increased expression of proliferation related genes, the promotion of fibrosis and enhanced inflammation, and promoted immunosuppression through Tregs expansion in murine myometrium. We also showed that a vitamin D deficient diet enhanced DNA damage in murine myometrium.

Conclusion: Our model mimics the effects in humans that a lack of vitamin D has and propels the study of in vivo interaction between inflammation, genomic instability and cell proliferation in the myometrium.

Keywords: vitamin D, diet, inflammation, DNA damage, uterine fibroids

\section{Introduction}

Uterine fibroid (UF) is a serious health disparity as they are three to four times more prevalent in women of color compared to Caucasian women. Although there are many factors associated with an increased risk of UF development, such as nulliparity, early menarche, obesity and genetics, the race is considered to be one of the most important among them. We have reported that the estimated prevalence of UFs remains significantly higher in African-American women even after controlling for potential confounders such as parity and body mass index. ${ }^{1}$ These minority women also commonly suffer from vitamin D deficiency. ${ }^{2}$ There are limited dietary sources rich in vitamin D, such as fatty fish, fish oils and fortified foods; however, sunlight exposure remains the main source of vitamin D. ${ }^{3}$ That is likely why darkskinned individuals commonly suffer from vitamin D deficiency because their skin 
contains more melanin that equates to greater protection against ultraviolet radiation exposure. ${ }^{4,5}$

Additionally, we have shown recently that vitamin D inhibits in vitro UF cell proliferation by modulating multiple cellular pathways such as downregulation of catechol-Omethyltransferase (COMT), a key enzyme for clearance of catechol estrogens. ${ }^{6}$ Furthermore, our previous data showed that vitamin D3 suppressed TGF- $\beta 3$-induced fibrosis, Wnt/ $\beta$-catenin and mTOR as well as sex steroid receptors' gene expression in human fibroid cells. ${ }^{6-9}$ We have also demonstrated that $1,25(\mathrm{OH})_{2} \mathrm{D}_{3}$ attains an inhibitory impact on fibroid growth through its ability to block the G1/S (gap $1 /$ synthesis) phase of the cell cycle. Moreover, it regulates several cell cycle regulatory genes and modulates activities of cyclin-dependent kinases, leading to a reduced number of cells in the $\mathrm{S}$ phase and thus their accumulation in the G0-G1 phase. ${ }^{10,11}$

The association of vitamin $\mathrm{D}$ and vitamin $\mathrm{D}$ receptor (VDR) with DNA repair has been examined in the model of Ras-induced senescence. A functional relationship was demonstrated between the Ras oncogene, legend-mediated stability of VDR axis and the expression of DNA repair factors. ${ }^{12}$ Indeed, deficiency in vitamin D can create genomic instability that promotes tumorigenic transformation. ${ }^{13-15}$

Vitamin D is involved in immune response regulation, prevention of inflammation and autoimmunity, which are major risk factors for cancer progression. ${ }^{15-17}$ VDR exerts its anti-inflammatory effect via downregulation of NF-kBdependent production of proinflammatory cytokines and chemokines. ${ }^{18}$ The anti-inflammatory effect of vitamin $\mathrm{D}$ is also critical for maintaining tissue homeostasis. In addition, vitamin D plays a role in activation and differentiation of $\mathrm{T}$ cells as well as regulation of autophagy and antibacterial function of monocytes and macrophages. ${ }^{19-21}$ Recently, we reported that autophagy is abrogated in human UFs due to defective expression in Atg4D. ${ }^{22}$ Based on studies by us and other investigators, vitamin D deficiency is poised to be an important risk factor for myometrial transformation secondary to chronic inflammation that likely leads to genomic instability and accumulation of abnormalities in the DNA repair machinery.

Since most studies have examined the effect of vitamin D deficiency on fibroid development using in vitro cell lines, we used an in vivo mouse model with vitamin D-deficient diet to verify and validate the effect of vitamin D deficiency on inflammation, genomic instability and proliferation of myometrium. This model recapitulates myometrial changes in humans with vitamin D deficiency, and thus, data from this study can have a high translational impact.

\section{Materials and methods}

\section{Induction of vitamin D deficiency in mice}

Female C57BL/6 mice, 4-6 weeks old, were divided into two groups: control group $(n=10)$ fed on normal diet (Purina \#5053) containing vitamin D of $4 \mathrm{IU} / \mathrm{g}$ versus vitamin D-deficient diet group ( $\mathrm{n}=10$; Purina \#5B7Q) totally lacking vitamin D for 8 weeks. The diet was obtained from Charles River Laboratories. All animal procedures were conducted in accordance with the National Institutes of Health Guidelines, and mice were housed in facilities accredited by the Association for Assessment and Accreditation of Laboratory Animal Care. All animal experiments were approved by the animal committee of Augusta University Institutional Animal Care and Use Committee (IACUC). At the end of the experiment, all animals were euthanized. Blood was collected by cardiac puncture under inhalation anesthesia prior to euthanasia to measure serum vitamin D and estrogen (E2). Myometrial tissues were collected from two groups, the endometrium was opened, scrubbed and divided into two samples, one was immediately snap frozen in liquid nitrogen and then stored at $-80^{\circ} \mathrm{C}$ and the other was fixed in $10 \%$ buffered formalin for immunohistochemistry.

\section{Immunohistochemistry}

Paraffin-embedded tissue sections $(4 \mu \mathrm{m})$ were deparaffinized and rehydrated by passing through xylene and graded ethanol solutions as previously described. ${ }^{23}$ Sex steroid receptors were evaluated by staining with progesterone receptor A (PRA) and progesterone receptor $B(P R B)$ and ER-alpha (ER- $\alpha)$. Cell proliferation was analyzed by staining with immunoreactive proliferating cell nuclear antigen (PCNA) and a cell proliferating marker Ki-67. Apoptosis in myometrial tissues was evaluated using histochemical staining with anti-caspase 3 antibody. Fibrosis-related receptors were evaluated by using TGF $\beta$ R2. DNA damage was evaluated by staining with immunoreactive DNA damage marker $\gamma \mathrm{H} 2 \mathrm{AX}$, RAD50 and RAD51. For the quantification, we compared the two groups (control group and vitamin D3-deficient group) by taking 10 fields of each, counting the number of positive cells (brown staining) and calculating the percentage of positivity of each antibody by dividing the brown nucleus by the total numbers of the nucleus in one field and then taking the average.

\section{Western blot}

Frozen myometrial tissues were homogenized and sonicated in sodium dodecyl sulfate polyacrylamide gel electrophoresis (SDS-PAGE) lysis buffer. Preparation of protein lysates and Western blot analyses were performed as previously described by Halder et al. ${ }^{24}$ Briefly, the crude lysates were centrifuged 
at $13,000 \mathrm{rpm}$ for $20 \mathrm{~min}$ at $4^{\circ} \mathrm{C}$. The clear protein lysates were transferred into new Eppendorf tubes, and protein concentrations were determined using Bio-Rad protein assay reagents according to the manufacturer's instructions. Equal amounts of each protein lysate $(30-40 \mu \mathrm{g})$ were resolved by $10 \%$ SDS-PAGE and transferred onto the polyvinylidene fluoride membrane. Western blot analyses were performed to assess the expressions of sex steroid receptors using antiPR-A (1:300), anti-PR-B (1:300) and anti-ER- $\alpha$ (1:500); cell growth and proliferation markers using anti-PCNA (1:500) and anti-cyclin D1 (1:500); and apoptotic markers using anti-PARP (1:500) antibodies. Fibrosis-related markers were evaluated using TGF $\beta$ R2 (1:500). The antigen-antibody complex was detected using an enhanced chemiluminescence detection system (Amersham Bioscience, Piscataway, NJ, USA). Specific protein bands were visualized after exposure to autoradiography films and development using an automatic X-ray developer. Sample protein quantification of Western blot data was calculated as a ratio to actin level via densitometry. Densitometry analysis was performed using Image Studio software (Lincoln, NE, USA).

\section{Flow cytometry}

The infiltrating immune cells of the myometrium were stained for the common marker CD45. The regulatory T cells (Tregs) were stained by their specific markers CD4 and Foxp3. The quantification of suppressive cytokines released by Tregs was performed based on TGF- $\beta$ and IL-10 intracellular staining after fixation and permeabilization using Fix/Perm kit (BD Biosciences, San Jose, CA, USA). The intracellular staining for cytokines was done in the presence of GolgiStop (BD Biosciences). A total of $1 \times 10^{5}$ cell line cells were incubated with the Abs for $30 \mathrm{~min}$ at room temperature. The cells were washed twice with $\mathrm{PBS} / 2 \%$ fetal bovine serum (FBS) (v/v) and re-suspended. Samples were acquired and analyzed using the FACSCanto (BD Biosciences) and FlowJo systems (Ashland, OR, USA).

\section{Real-time polymerase chain reaction (PCR)} Total RNAs were isolated by using TRIzol reagent (Thermo Fisher Scientific, Waltham, MA, USA) according to the manufacturer's instructions. RNA was extracted from frozen myometrium tissue. A total of $1-5 \mu \mathrm{g}$ of total RNA was reverse transcribed using SuperScript III Reverse Transcriptase (Thermo Fisher Scientific) to prepare cDNA. Real-time PCR was performed by using iTaq Universal SYBR Green Supermix (Bio-Rad Laboratories Inc., Hercules, CA, USA) for murine TGF- $\beta$, IL-10 and $\beta$-actin using specific primers (Table S1). The amplification was done on Bio-Rad quantitative polymerase chain reaction (qPCR) machine
(Bio-Rad Laboratories Inc.). The results are represented as an expression relative to actin.

\section{Radioimmunoassay (RIA)}

Sera were analyzed for E2 using the RIA method previously validated in our laboratory. ${ }^{25}$ The sensitivity of E2 assay was $2 \mathrm{pg} /$ tube, and the intra- and inter-assay coefficients of variation (CVs) were $4.9 \%$ and $10.8 \%$, respectively. Sera were also analyzed for vitamin D (25 hydroxy vitamin D) level. The vitamin D assay involves a rapid extraction of vitamin D from serum or plasma with acetonitrile. The extracted sample was assayed using an equilibrium RIA procedure based on an antibody that is co-specific for vitamin D. The assay has a range of $2.5-100 \mathrm{ng} / \mathrm{mL}$ and intra- and interassay CVs of $8.0 \%$ and $10.0 \%$, respectively. Measurement of vitamin D was done at Heartland Assays (Ames, IA, USA) and that of E2 was done at Ligand Assay and Analysis Core Laboratory (Charlottesville, VA, USA).

\section{Statistical analyses}

All statistical analyses were performed using paired $t$-tests. The paired $t$-test was used to assess the significance of differences between the two groups. Values were considered to be statistically significant when $P$ was $<0.05$.

\section{Results}

\section{Vitamin D-deficient diet effectively induces vitamin $D$ deficiency in mice}

Our experimental design aimed to induce in vivo vitamin $\mathrm{D}$ deficiency through a vitamin D-deficient diet (Figure 1A). At 8 weeks after feeding, we measured the serum levels of vitamin D in both groups using the standard RIA technique as described before. ${ }^{25}$ We observed that the serum level of vitamin $\mathrm{D}$ in the deficient group was significantly decreased $(P<0.05)$ compared to the control group (Figure 1B). Decreased levels of vitamin D in mice did not affect serum estradiol level as reported previously, ${ }^{26,27}$ and there was no significant difference between vitamin D-sufficient and -deficient mice (Figure 1C). After 8 weeks of mice exposure to vitamin D-deficient diet, the mice appeared healthy with normal uterus weight compared to the control group with the absence of morbidity or mortality.

\section{Vitamin D deficiency is associated with increased expression of sex steroid receptors in murine myometrium}

We were then set to examine if vitamin $\mathrm{D}$ deficiency induces a pre-fibroid status in the myometrium of affected mice. To this end, we examined several parameters that are characteristic of 
A

No Vit D diet exposure

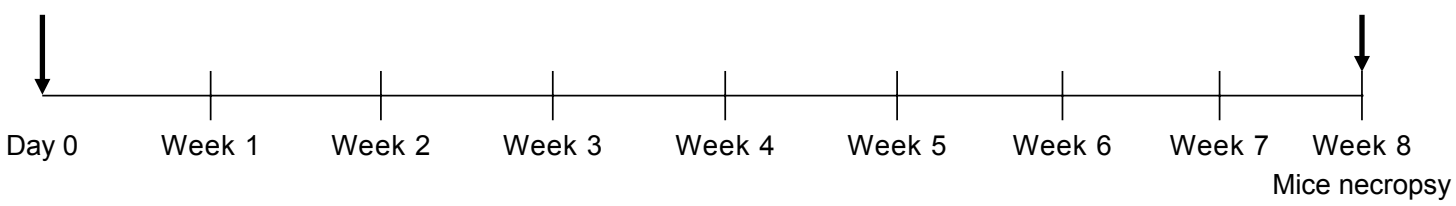

B

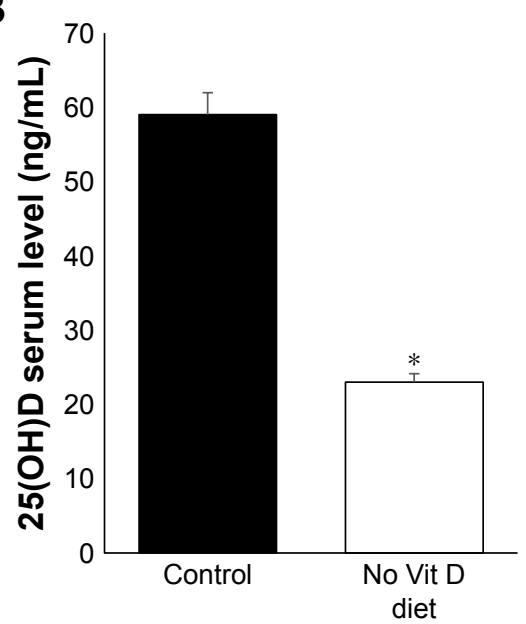

C

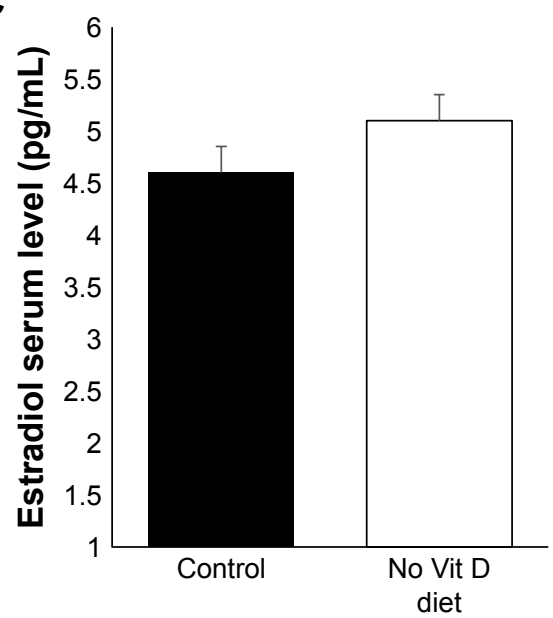

Figure I In vivo levels of vitamin D and estradiol.

Notes: (A) Study design of mice exposition to deficient vitamin D diet for a time period of 8 weeks. Mice serum level of vitamin D (B) and estradiol D3 (C) from vitamin D deficiency and control groups $(n=10)$ were measured using RIA $(* P \leq 0.05)$.

Abbreviation: Vit, vitamin.

fibroid tumors (ie, increased sex steroid receptor expression and proliferation, decreased apoptotic cell death, increased production of extracellular matrix and enhanced inflammation as well as DNA damage). Using Western blot, we first examined the effect of vitamin D deficiency on the levels of sex steroid receptor expression in the myometrium using tissues collected from the two groups. Our results showed a significant increase in PRA $(P<0.05)$, PRB $(P<0.05)$ and ER- $\alpha(P<0.05)$ expression levels in the vitamin D deficiency group compared to the control group, semiquantified by densitometry (Figure 2A and B). These data were supported by immunohistochemistry using specific antimouse antibodies against PRA, PRB and ER- $\alpha$ antibodies. Antibody-positive stained cells were much more abundant in the vitamin D-deficient group when compared to the control group, and the difference was highly significant, especially for PRB $(P<0.005$; Figure $2 \mathrm{C}$ and $\mathrm{D})$.

\section{Vitamin D deficiency increases expression of proliferation-related genes PCNA and cyclin DI in murine myometrium}

To examine the effects of vitamin D deficiency on the basal level of myometrial cell proliferation in affected mice, we analyzed expression of proliferation gene, PCNA and cell cycle marker, cyclin D1, by Western blot analyses using myometrial tissues from the two groups. We found that vitamin D deficiency significantly increased the protein expression of PCNA and cyclin D1 genes compared to healthy controls $(P<0.05$; Figure $3 \mathrm{~A}$ and $\mathrm{B})$. Consistent with the immunoblot data, immunohistochemistry staining demonstrated significantly a higher percentage of PCNA positive cells and $\mathrm{Ki}-67^{+}$cells (marker of cell proliferation) in the treated group when compared to the control group $(P<0.05$; Figure $3 \mathrm{C}$ and $\mathrm{D})$.

\section{Vitamin D deficiency decreases the expression of apoptosis-related genes in murine myometrium}

Decreased apoptotic cell death is an important feature of UF lesions. We investigated here the impact of vitamin D deficiency on the apoptosis of myometrial cells in affected mice by comparing the levels of proapoptotic genes PPAR and caspase-3 in myometrium. Immunoblot analysis showed a significant inhibition of PARP in the myometrial tissues of vitamin D-deficient mice when compared to healthy controls $(P<0.05$; Figure 4A). In addition, immunohistochemistry analysis demonstrated a significantly lower expression of caspase-3 ( $P<0.05$; Figure 4B) in the myometrial tissues of vitamin D-deficient mice when compared to healthy controls. 


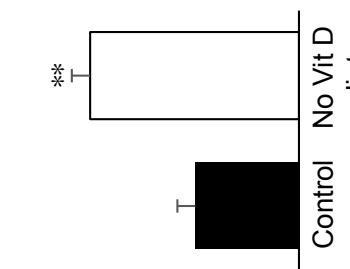

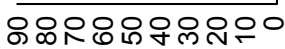

$\forall$ पdd JOf S||əo

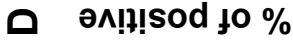

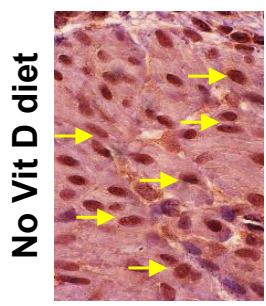

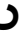
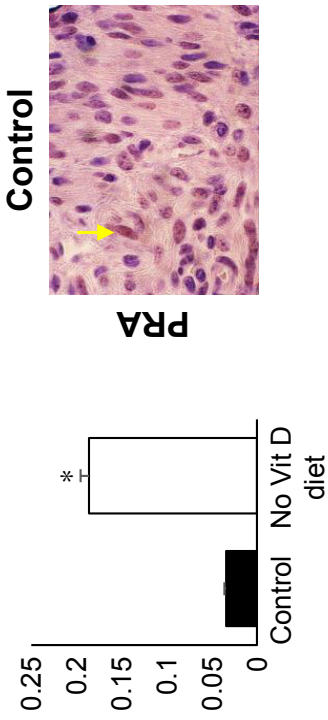

ł! un

m Kuest!que $\forall$ yd

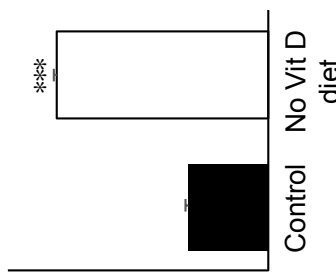

응 웅

gyd 10\} s||əo

pəu!lęs to \%
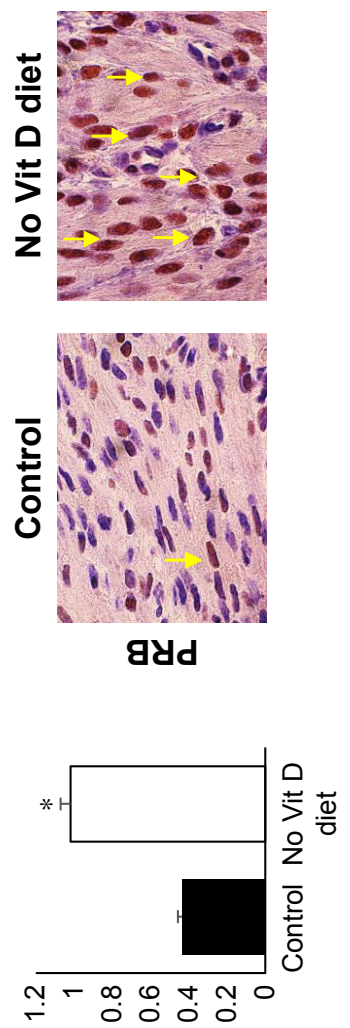

भ! un

Kuest!que gyd
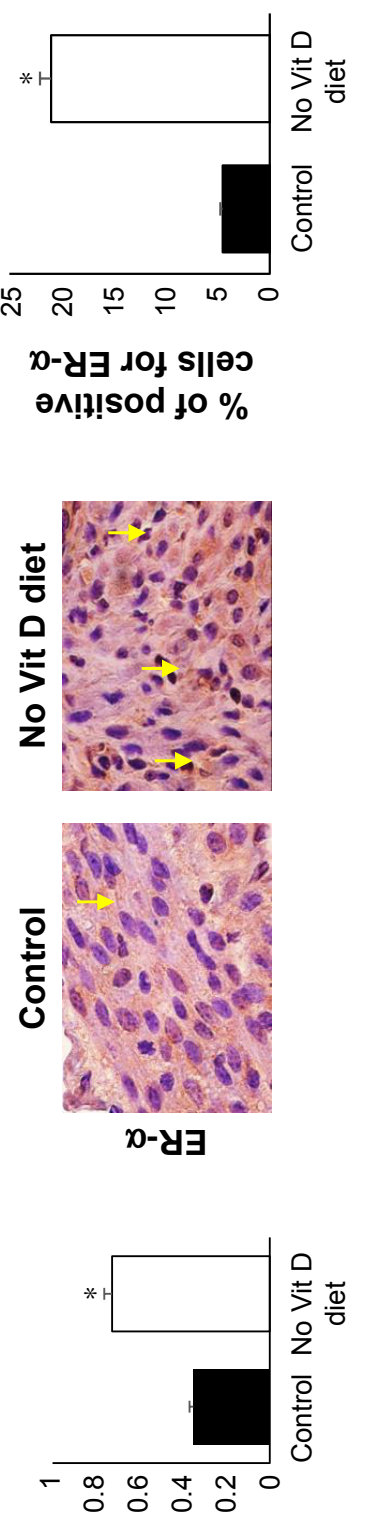

भ! un

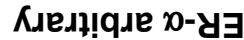

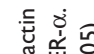

뭉

可 V

的紊

ธ。

覀这

S

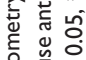

离

入ิ는

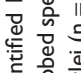

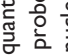

政

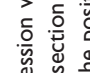

文部

凉

일

鱼

密密

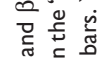

앙 궁

岦然

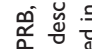

政

萡

鹿

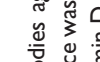

을 㫐

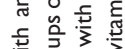

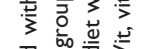

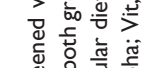

वे

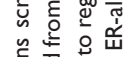

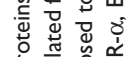

产范岩占

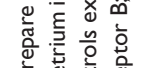

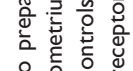

品 हो

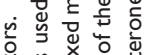

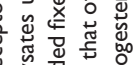

늘

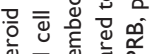

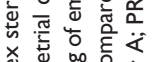

วə!̣ a $7 ! \wedge$ ON

†ə!p व $\because ! \Lambda$ ON

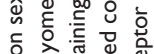

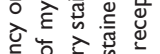

ןодฺนоว

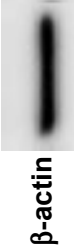

ןодฺนоว

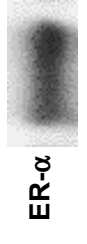

$\varangle$

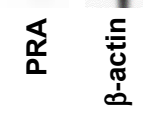

势

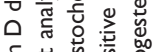

들 흥

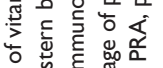

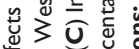

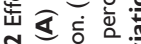

政 
A
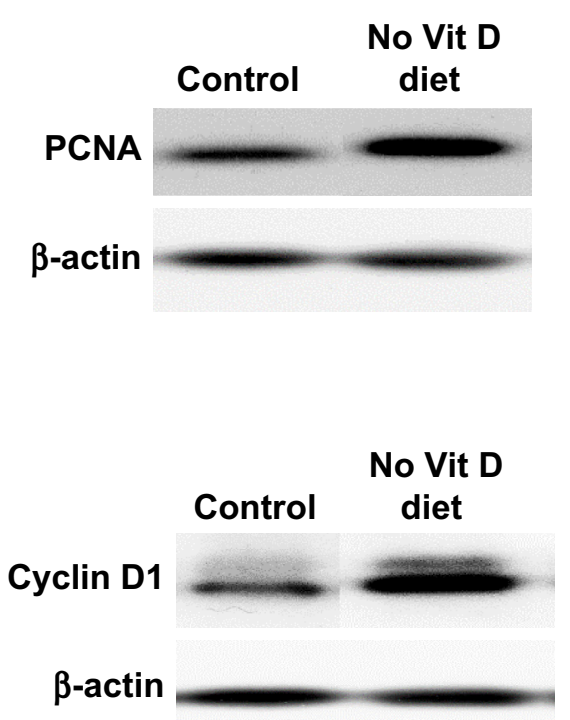

C
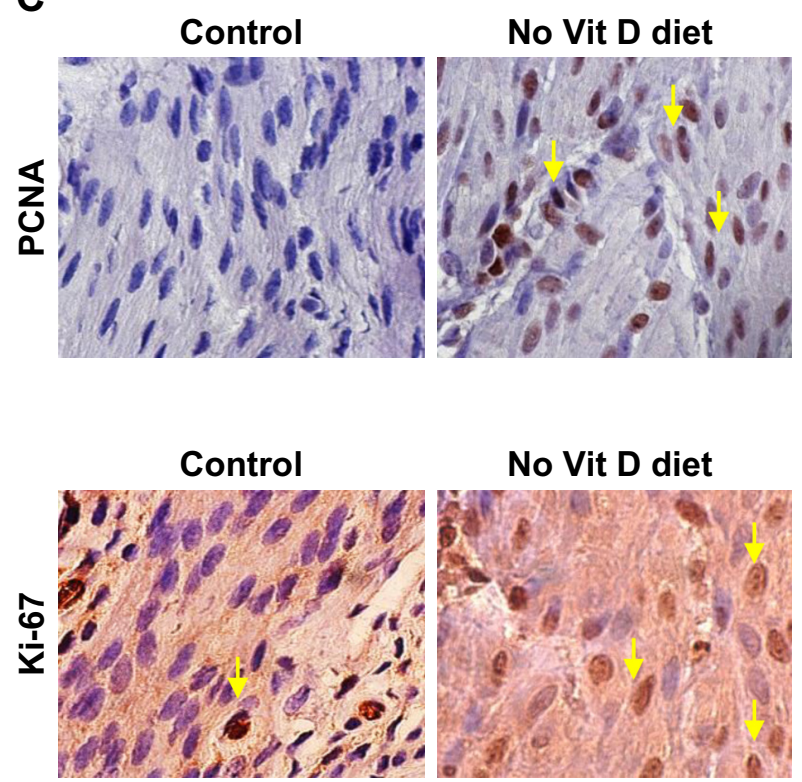
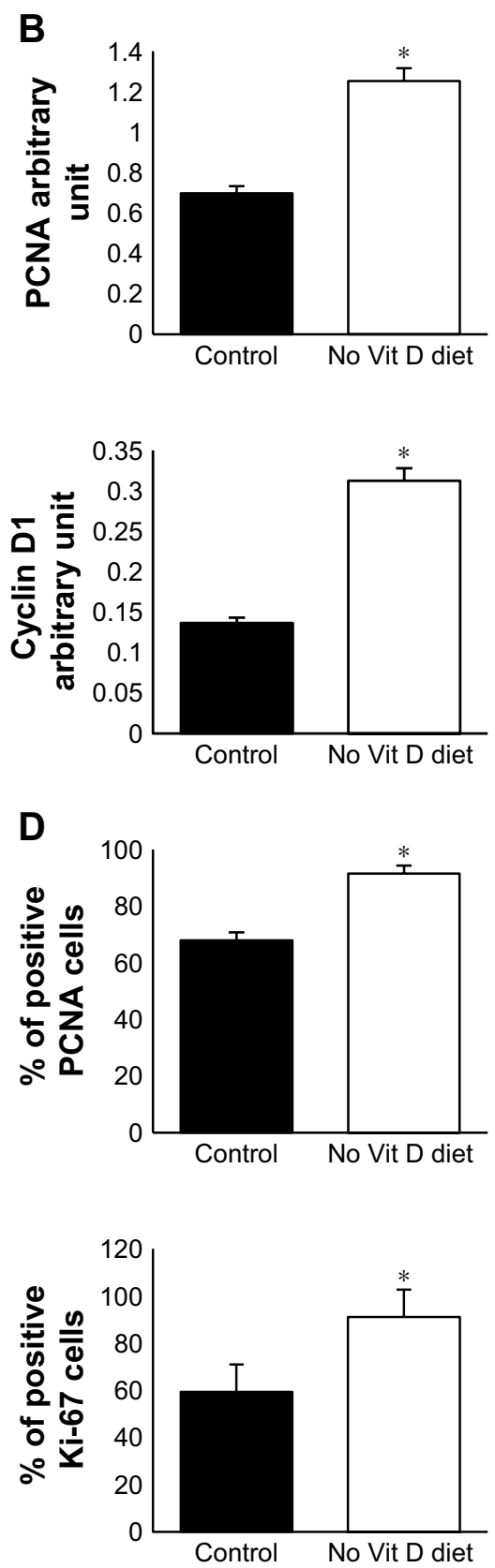

Figure 3 Antiproliferative effects of vitamin D.

Notes: (A) Western blot analyses with mouse anti-PCNA, anti-cyclin DI, marker of cell cycle and anti- $\beta$-actin. (B) Protein densitometry analysis was done as described in the Materials and methods section. (C) Immunohistochemical analysis of myometrial tissues of vitamin D deficiency and control groups stained by anti-PCNA and antiKi-67. (D) The number of positive stained cells (brown nuclei). Black arrows point to the positive nuclei. All images were captured at $63 \times$ magnification, scale bar $200 \mu \mathrm{m}$ ) $(* P \leq 0.05)$

Abbreviations: PCNA, proliferating cell nuclear antigen; Vit, vitamin.

\section{Vitamin D deficiency increased expression of fibrosis-related genes}

Vitamin D supplementation in vitamin D-deficient women with reproductive disorder significantly decreases the bioavailability of TGF- $\beta 1 .^{28}$ To test the effect of vitamin D deficiency on fibrosis-related receptor expression, we performed Western blot analysis using myometrial tissues from two groups. We observed that the expression level of TGF $\beta$ R2 was significantly increased in the vitamin $\mathrm{D}$ deficiency group compared to healthy controls $(P<0.05$; Figure $4 \mathrm{C})$. These data were supported by immunohistochemistry analysis $(P<0.005)$. TGF $\beta$ R2 receptors were expressed at higher levels in the nuclei of myometrium cells in vitamin D-deficient group compared to control group (Figure 4D). These data suggest that vitamin $\mathrm{D}$ is antifibrogenic as it modulates the expression of TGF $\beta$ R2, a major pro-fibrotic mediator. ${ }^{29}$ 
A

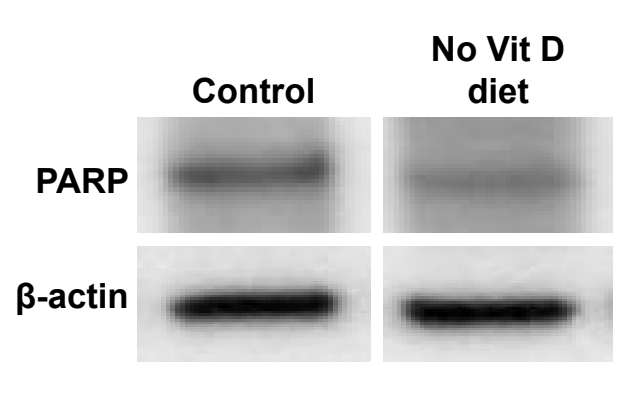

B

C
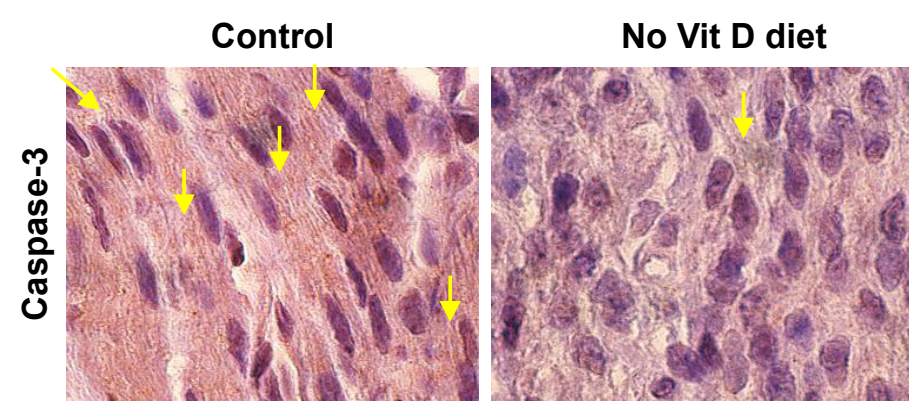

D

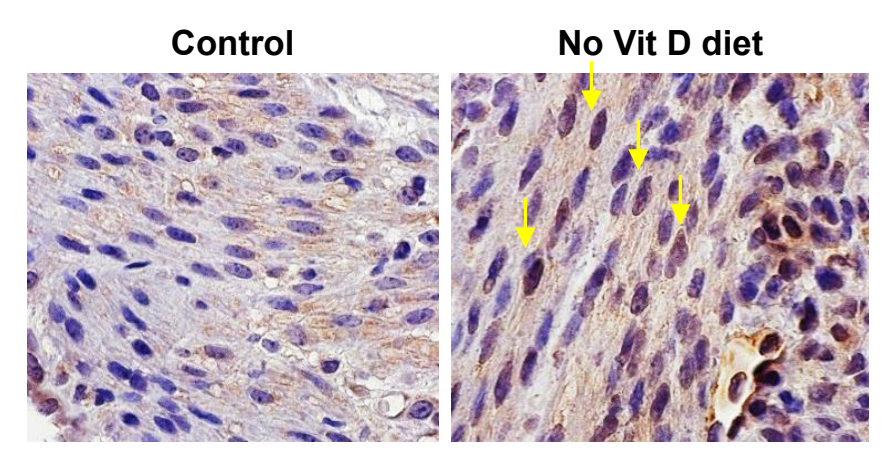

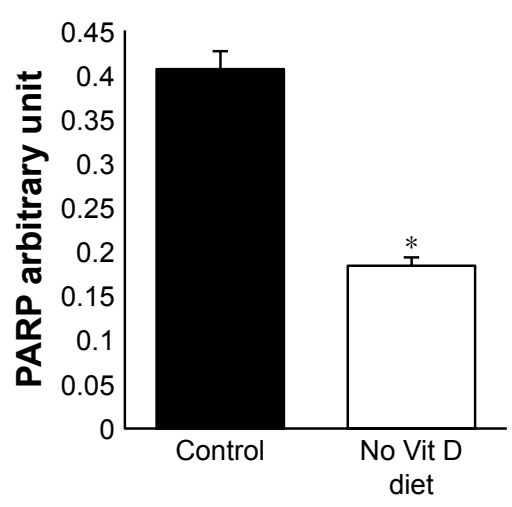
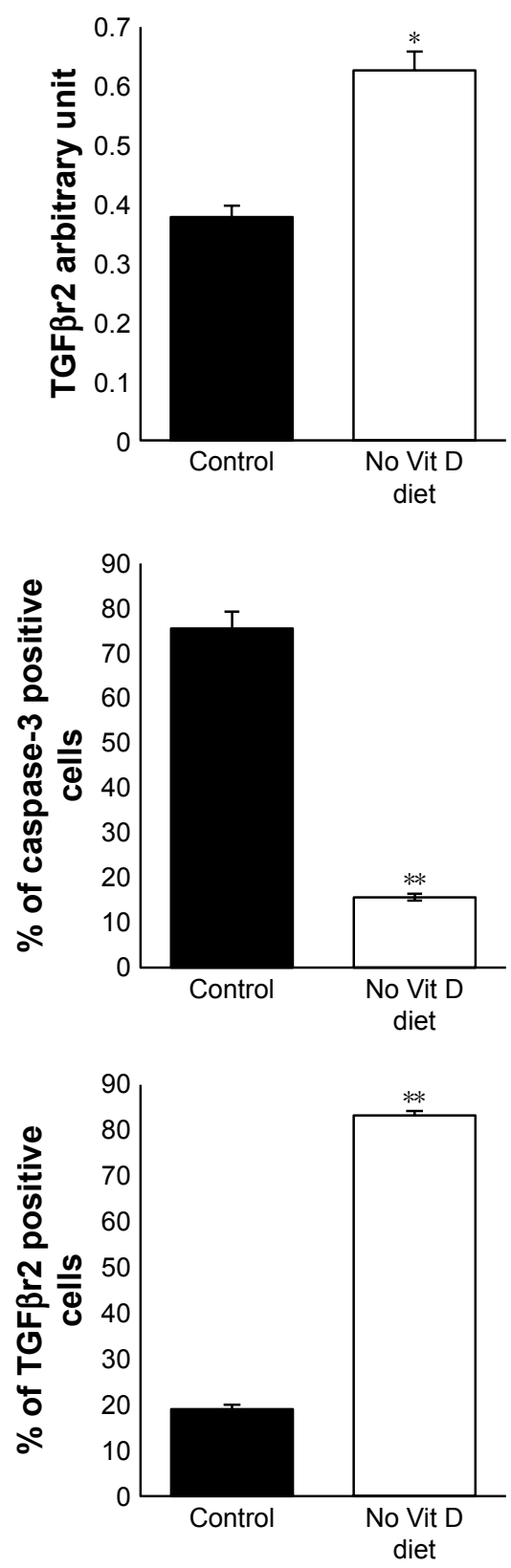

Figure 4 Vitamin D deficiency inhibits apoptosis and enhances TGF $\beta R 2$ in myometrium.

Notes: (A) Western blot of PARP using mouse anti-PARP antibody. (B) TGF $\beta 22$ Western blot using mouse anti-TGF $\beta R 2$ antibody supported by quantification analysis by densitometry. (C) Immunohistochemical analysis for apoptosis marker caspase-3 using mouse anti-caspase-3. (D) Immunohistochemical analysis for fibrosis in myometrium tissue using mouse anti-TGF $\beta$ R2. All images were captured at $63 \times$ magnification, scale bar $200 \mu \mathrm{m}$. The number of stained cells (brown nuclei) was counted in five random high power fields, and the average number of cells is presented in bar graph. Yellow arrows point to the stained nuclei $(n=10, * P \leq 0.05, * * P \leq 0.005)$. Abbreviation: Vit, vitamin. 


\section{Vitamin $D$ deficiency enhances} inflammation and promotes immunosuppression through expansion of Tregs in murine myometrium

Vitamin D is an important player in the regulation of inflammation. We hypothesized that vitamin D deficiency may impair infiltration and/or expansion of Tregs in the myometrium, which in turn could lead to uncontrolled inflammation. To test this hypothesis, we examined the frequency of effectors and Tregs in the myometrium using flow cytometry. Cells were stained with anti-CD45 (markers of mononuclear cells) antibody, and $\mathrm{CD} 45^{+}$cells were gated and further analyzed for expression of Foxp3 (intracellular transcription factor in Tregs; Figure 5A and B). Our data show a significant increase in the percentage and mean fluorescence intensity (MFI) of infiltrating $\mathrm{CD} 45^{+} \mathrm{Foxp}^{+}$cells in the myometrium from vitamin D-deficient group compared to the healthy control group $(P<0.05)$. As the suppressive function of Tregs is defined based on their production of suppressive cytokines of immune response such as TGF- $\beta$ and IL-10, we analyzed the percentage of Tregs expression in TGF- $\beta$ and IL-10. Our data show that the vitamin D-deficient group has a significantly higher percentage of Tregs producing TGF- $\beta$ and IL-10 than that detected in the healthy control group (Figure 5C). Furthermore, we examined the expression of TGF- $\beta$ and IL-10 mRNA in the myometrium by quantitative reverse transcription polymerase chain reaction (qRT-PCR) and detected significantly increased levels of TGF- $\beta$ and IL-10 expression in the vitamin D deficiency group compared to the healthy control group $(P<0.05)$, which is consistent with the fluorescence-activated cell sorting (FACS) data (Figure 5D and E). Together, these data suggest that vitamin $\mathrm{D}$ deficiency alters the tumor microenvironment in a manner that promotes inflammation.

\section{Vitamin D deficiency enhanced DNA damage in murine myometrium}

Under the absence of vitamin $\mathrm{D}$, the myometrium milieu becomes proinflammatory and promotes the conversion and expansion of Tregs from naïve CD4 T cells, which is signature
A
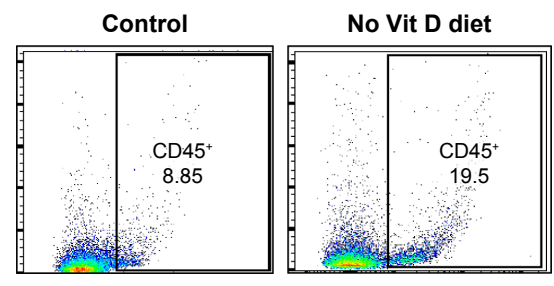

B

CD4 $^{+}$Foxp3 $^{+} \mathrm{T}$ cells

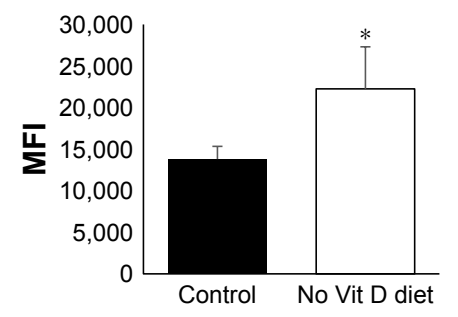

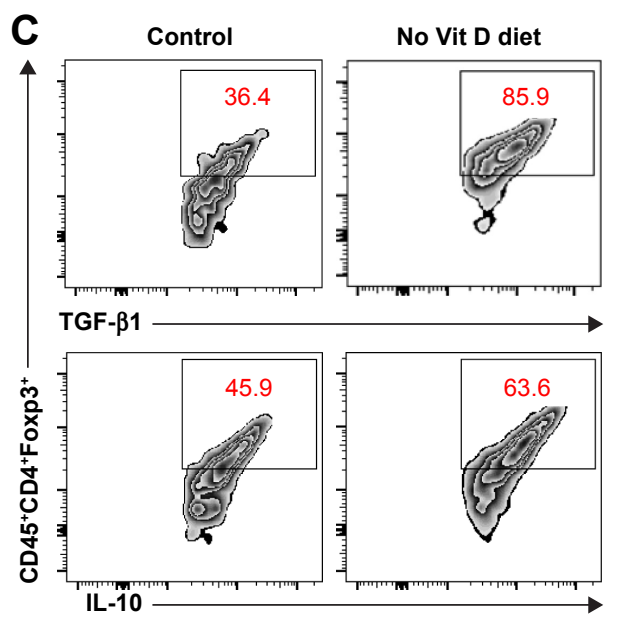
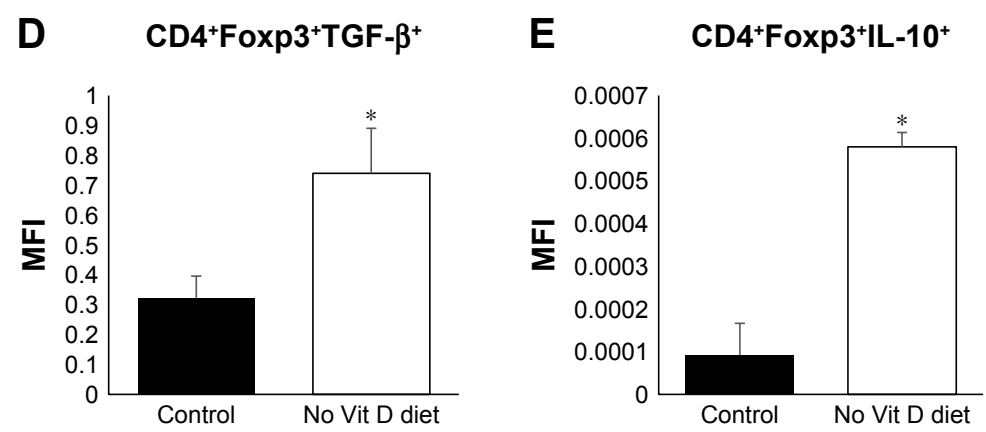

Figure 5 Role of vitamin $D$ in the immune homeostasis of myometrium milieu.

Notes: (A) Flow cytometry analysis of myometrium total CD45 $5^{+}$immune cells' infiltration. (B) MFI analysis after intracellular staining of Foxp $3^{+}$Tregs marker gating on CD 45 ${ }^{+} C D 4^{+} \mathrm{T}$ cells. (C) Percentage of positive Tregs for TGF- $\beta$ I (upper panels) and IL-10 (lower panels) based on intracellular staining and FACS analysis with MFI of (D) TGF- $\beta$ I and (E) IL- I0, respectively $(n=10, * P \leq 0.05)$.

Abbreviations: MFI, mean fluorescence intensity; Tregs, regulatory T cells; Vit, vitamin. 

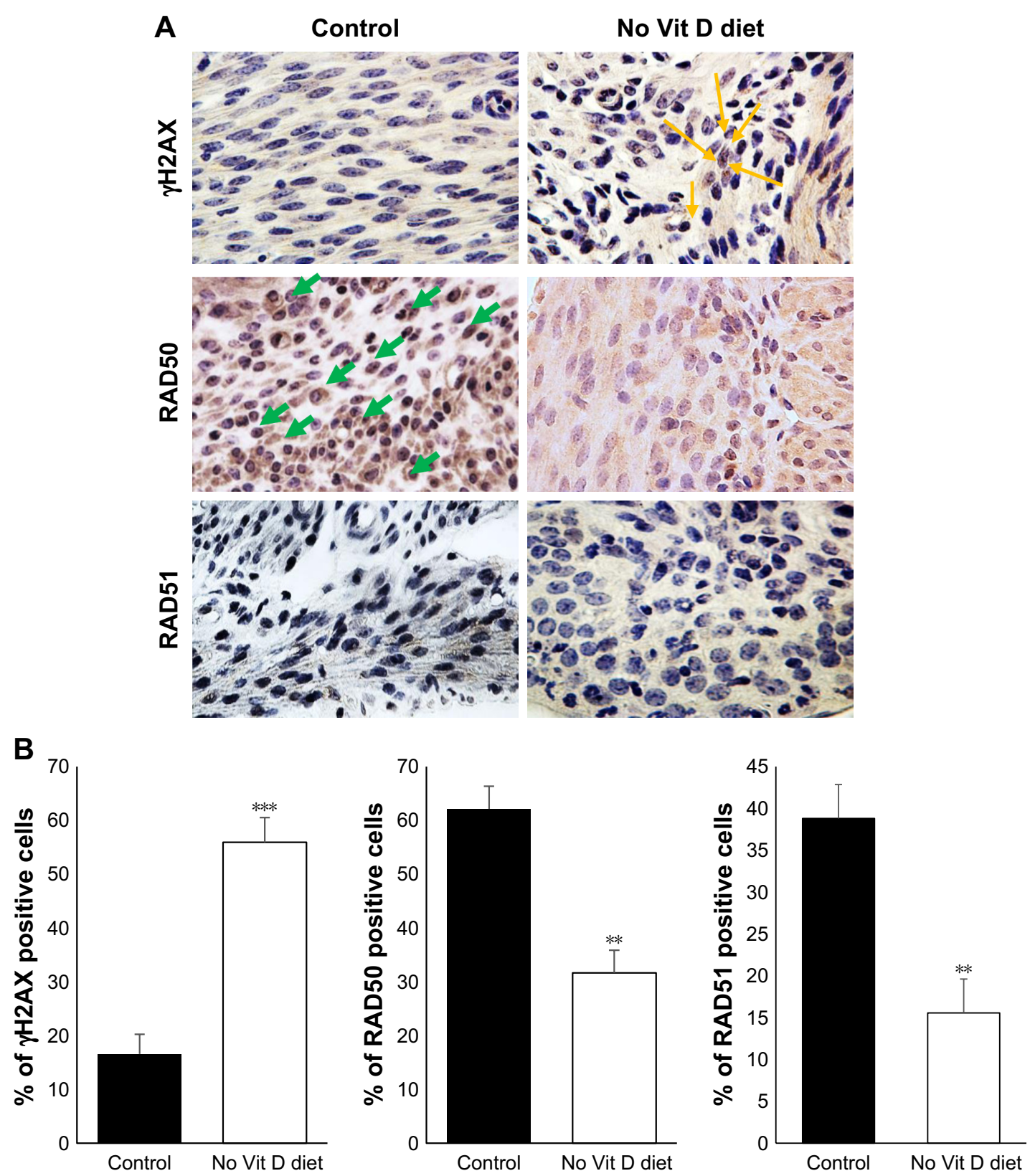

Figure 6 Vitamin D-deficient diet increases DNA damage in mice myometrium.

Notes: (A) Immunohistochemical analyses of myometrial tissues of vitamin D deficiency and control groups by DNA damage marker $\gamma \mathrm{H} 2 \mathrm{AX}$ and DNA repair genes RAD50 and RAD5I. All images were captured at 63× magnification, scale bar $200 \mu \mathrm{m}$, yellow arrows indicate YH2AX, green arrows indicate RAD50. (B) The degrees of DNA damage and DNA repair were scored by counting the $\gamma \mathrm{H} 2 \mathrm{AX}, \mathrm{RAD} 50$ and RAD5I positive nuclei. The percentage of positive cells was calculated based on the number of stained cells, counted in a total of five random high-power fields in the representative myometrium of control and vitamin D3-deficiency samples. The average number of cells is presented $(\mathrm{n}=10, * * \mathrm{P}<0.005$ and $* * * \mathrm{P}<0.0005)$

Abbreviation: Vit, vitamin.

of the tumoral microenvironment initiating transformation from normal myometrium tissue to malignancies. This can promote genomic instability characterized by defects in DNA repair and accumulation of DNA damage. ${ }^{30,31}$ To test whether vitamin D deficiency initiates DNA damage in myometrial tissues, we performed immunohistochemical analyses using immunoreactive $\gamma \mathrm{H} 2 \mathrm{AX}$ (a DNA damage marker) via polyclonal anti- $\gamma \mathrm{H} 2 \mathrm{AX}$ antibodies (Figure 6A). Vitamin Ddeficient mice demonstrated a remarkable increase in $\gamma \mathrm{H} 2 \mathrm{AX}$ in myometrium tissues compared to healthy controls $(P<0.05$; Figure 6B). Conversely, vitamin D deficiency induced a significant decrease in the expression of DNA repair genes such as RAD50 $(P<0.005)$ and RAD51 $(P<0.005)$ compared to healthy controls (Figure 6B). 


\section{Discussion}

Our study provides a new model to explore the role of vitamin $\mathrm{D}$ in the homeostasis of myometrium and associated diseases such as UFs. The relationship between vitamin D deficiency and increased risk of UF was confirmed in several studies including our published data. ${ }^{4,32,33}$ A significant inverse relationship between vitamin $D$ serum levels and the severity of fibroids was reported in African-American females, with a higher disease burden detected in patients with low vitamin $\mathrm{D}$ levels. ${ }^{4}$ The involvement of vitamin $\mathrm{D}$ in myometrial biology was not examined in vivo previously. Our model of vitamin D lacking function using 8-week exposure of C57/BL6 mice to vitamin D-deficient diet provides evidence of different functions accomplished by vitamin $\mathrm{D}$ in the murine uterus. To date, numerous biologic functions have been reported for vitamin $\mathrm{D}$, including control of proliferation, inflammation, autoimmunity, DNA damage/repair and tumorigenesis. Our results demonstrate that vitamin $\mathrm{D}$ diet supplementation generates $80 \%$ of circulating vitamin $\mathrm{D}$ in the blood stream of the mice and the remaining $20 \%$ are generated from other sources. In addition, the present study establishes vitamin D as a key molecule controlling sex steroid receptors, myometrium cell proliferation, cytokine release and inflammation and DNA repair in damaged cells in the murine myometrium.

Vitamin D exerts anti-inflammatory action by controlling TGF- $\beta$ and IL-10 to prevent immunosuppression and protect the myometrium from transformation and tumorigenesis. Thus, vitamin $\mathrm{D}$ deficiency promotes inflammation in myometrium milieu and promotes the conversion and expansion of Tregs from naïve $\mathrm{CD} 4 \mathrm{~T}$ cells (a signature of tumor microenvironment). This initiates or, more likely, promotes transformation of normal myometrium tissue to neoplasia after a mutagenic event takes place, such as fibroid-causing Med12 mutations in human fibroids. ${ }^{34}$ Indeed, previous studies have shown that vitamin D induces autophagic cell death of cancer cells, indicating the potential for vitamin D as an anti-fibroid treatment. ${ }^{35,36}$ In the present study, we demonstrate that hypovitaminosis $\mathrm{D}$ induces the expression of progesterone receptors PRA and PRB and ER- $\alpha$. Our data confirm our previous observation of an inverse correlation between the upregulated ER- $\alpha$, PR-A and PR-B and expression of VDR in UFs. ${ }^{37}$ We also showed that treatment with vitamin D significantly decreased levels of ER- $\alpha$, PRA and PRB. ${ }^{17}$ Moreover, Wu et al reported that PR-A was overexpressed in fibroid tissue of African-American females compared to those of other ethnic groups. This is consistent with the higher prevalence of hypovitaminosis D in African-American women. ${ }^{2}$ The current data show that vitamin $\mathrm{D}$ regulates cell survival and death by controlling PCNA, PARP and caspase-3. Control of growth rate of the myometrium by vitamin $\mathrm{D}$ prevents the development of fibrosis and establishment of chronic inflammation. Our in vivo model also confirms our prior in vitro observation that vitamin D exhibits antifibrogenic effects and modulates the profibrotic mediator TGF $\beta R 2 .{ }^{17}$ To date, numerous studies showed the relationship of VDR and DNA repair. It is established that vitamin D treatment stabilizes VDR, BRCA1 and 53BP1 levels, preventing the recruitment of these DNA repair factors to sites of damage in senescent cells. ${ }^{38}$ Our present data demonstrate that lack of vitamin D in vivo induces the phosphorylation of $\gamma \mathrm{H} 2 \mathrm{AX}$, indicating accumulation of DNA damage and genomic instability while significantly decreasing RAD50 and RAD51 as markers of DNA repair genes. These results suggest that vitamin D3 deficiency exacerbates DNA damage in myometrium and activate UF cell growth through the reduction of DNA repair capacity. Association of DNA damage and uncontrolled proliferation, in the presence of chronic inflammation, will create a tumorigenic niche. To date, it is established that tumor escape from immune response is due to the immunosuppressive milieu. ${ }^{39,40}$ Studies have shown that the tumor produces a high amount of suppressive cytokines (eg, TGF- $\beta$, IL-10), responsible for Tregs conversion and proliferation, which suppresses the tumor immune response. ${ }^{41-43}$ However, vitamin D supplementation in vitamin D-deficient women with reproductive disorder significantly decreases the bioavailability of TGF- $\beta 1 .{ }^{17}$

\section{Conclusion}

Our model validates our hypothesis that vitamin D deficiency can work as a pro-tumorigenic promoting factor by starting the first hit to render the myometrial tissue more vulnerable to leiomyoma development, likely after the emergence of a driver mutation such as Med12. The current results extend our previous work on the pivotal role of vitamin D deficiency in the pathogenesis of UF and establish the existence of an interconnection between inflammation and DNA damage promoting myometrial proliferation.

\section{Acknowledgment}

This study was supported by grant NIH-R01.

\section{Disclosure}

The authors report no conflicts of interest in this work.

\section{References}

1. Catherino WH, Eltoukhi HM, Al-Hendy A. Racial and ethnic differences in the pathogenesis and clinical manifestations of uterine leiomyoma. Semin Reprod Med. 2013;31(5):370-379. 
2. Nesby-O’Dell S, Scanlon KS, Cogswell ME, et al. Hypovitaminosis D prevalence and determinants among African American and white women of reproductive age. Third National Health and Nutrition Examination Survey, 1988-1994. Am J Clin Nutr. 2002;76(1):187-192.

3. Holick MF. Too little vitamin D in premenopausal women: why should we care? Am J Clin Nutr. 2002;76(1):3-4.

4. Sabry M, Halder SK, Allah AS, Roshdy E, Rajaratnam V, Al-Hendy A. Serum vitamin D3 level inversely correlates with uterine fibroid volume in different ethnic groups: a cross-sectional observational study. Int $J$ Womens Health. 2013;5:93-100.

5. Thota C, Laknaur A, Farmer T, Ladson G, Al-Hendy A, Ismail N. Vitamin D regulates contractile profile in human uterine myometrial cells via NFkappaB pathway. Am J Obstet Gynecol. 2014;210(4):347.e1-347.e10.

6. Halder SK, Goodwin JS, Al-Hendy A. 1,25-Dihydroxyvitamin D-3 reduces TGF-beta 3-induced fibrosis-related gene expression in human uterine leiomyoma cells. J Clin Endocrinol Metab. 2011;96(4):E754-E762.

7. Halder SK, Osteen KG, Al-Hendy A. 1,25-dihydroxyvitamin d3 reduces extracellular matrix-associated protein expression in human uterine fibroid cells. Biol Reprod. 2013;89(6):150.

8. Al-Hendy A, Diamond MP, Boyer TG, Halder SK. Vitamin D3 inhibits Wnt/beta-catenin and mTOR signaling pathways in human uterine fibroid cells. J Clin Endocrinol Metab. 2016;101(4):1542-1551.

9. Brakta S, Diamond JS, Al-Hendy A, Diamond MP, Halder SK. Role of vitamin D in uterine fibroid biology. Fertil Steril. 2015;104(3): 698-706.

10. Faerstein E, Szklo M, Rosenshein NB. Risk factors for uterine leiomyoma: a practice-based case-control study. II. Atherogenic risk factors and potential sources of uterine irritation. Am J Epidemiol. 2001; 153(1):11-19.

11. Marshall LM, Spiegelman D, Barbieri RL, et al. Variation in the incidence of uterine leiomyoma among premenopausal women by age and race. Obstet Gynecol. 1997;90(6):967-973.

12. Gonzalez-Suarez I, Redwood AB, Grotsky DA, et al. A new pathway that regulates 53BP1 stability implicates cathepsin $\mathrm{L}$ and vitamin $\mathrm{D}$ in DNA repair. EMBO J. 2011;30(16):3383-3396.

13. Chen J, Katz LH, Munoz NM, et al. Vitamin D deficiency promotes liver tumor growth in transforming growth factor-beta/Smad3-deficient mice through wnt and toll-like receptor 7 pathway modulation. Sci Rep. 2016;6:30217.

14. Fleet JC, DeSmet M, Johnson R, Li Y. Vitamin D and cancer: a review of molecular mechanisms. Biochem J. 2012;441(1):61-76.

15. Gocek E, Studzinski GP. Vitamin D and differentiation in cancer. Crit Rev Clin Lab Sci. 2009;46(4):190-209.

16. Heaney RP. Vitamin D in health and disease. Clin J Am Soc Nephrol. 2008;3(5):1535-1541.

17. Campbell FC, Xu H, El-Tanani M, Crowe P, Bingham V. The yin and yang of vitamin $D$ receptor (VDR) signaling in neoplastic progression: operational networks and tissue-specific growth control. Biochem Pharmacol. 2010;79(1):1-9.

18. Wu S, Liao AP, Xia Y, et al. Vitamin D receptor negatively regulates bacterial-stimulated NF-kappaB activity in intestine. Am J Pathol. 2010;177(2):686-697.

19. Miheller P, Muzes G, Hritz I, et al. Comparison of the effects of 1,25 dihydroxyvitamin $\mathrm{D}$ and 25 hydroxyvitamin $\mathrm{D}$ on bone pathology and disease activity in Crohn's disease patients. Inflamm Bowel Dis. 2009; 15(11):1656-1662.

20. Staeva-Vieira TP, Freedman LP. 1,25-dihydroxyvitamin D3 inhibits IFN-gamma and IL-4 levels during in vitro polarization of primary murine CD4+ T cells. J Immunol. 2002;168(3):1181-1189.

21. Sly LM, Lopez M, Nauseef WM, Reiner NE. 1alpha,25-Dihydroxyvitamin D3-induced monocyte antimycobacterial activity is regulated by phosphatidylinositol 3-kinase and mediated by the NADPH-dependent phagocyte oxidase. J Biol Chem. 2001;276(38): 35482-35493.

22. Andaloussi AE, Habib S, Soylemes G, et al. Defective expression of ATG4D abrogates autophagy and promotes growth in human uterine fibroids. Cell Death Discov. 2017;3:17041.
23. Al-Hendy A, Auersperg N. Applying the herpes simplex virus thymidine kinase/ganciclovir approach to ovarian cancer: an effective in vitro drugsensitization system. Gynecol Obstet Invest. 1997;43(4):268-275.

24. Halder SK, Beauchamp RD, Datta PK. Smad7 induces tumorigenicity by blocking TGF-beta-induced growth inhibition and apoptosis. Exp Cell Res. 2005;307(1):231-246.

25. Mohamed SA, El Andaloussi A, Al-Hendy A, et al. Vitamin D and corticotropin-releasing hormone in term and preterm birth: potential contributions to preterm labor and birth outcome. J Matern Fetal Neonatal Med. 2017;7:1-7.

26. Merhi Z, Doswell A, Krebs K, Cipolla M. Vitamin D alters genes involved in follicular development and steroidogenesis in human cumulus granulosa cells. J Clin Endocrinol Metab. 2014;99(6):E1137-E1145.

27. Bakhshalizadeh S, Amidi F, Alleyassin A, Soleimani M, Shirazi R, Shabani Nashtaei M. Modulation of steroidogenesis by vitamin D3 in granulosa cells of the mouse model of polycystic ovarian syndrome. Syst Biol Reprod Med. 2017;63(3):150-161.

28. Irani M, Seifer DB, Grazi RV, et al. Vitamin D supplementation decreases TGF-beta1 bioavailability in PCOS: a randomized placebocontrolled trial. J Clin Endocrinol Metab. 2015;100(11):4307-4314.

29. Abdelghany AH, BaSalamah MA, Idris S, Ahmad J, Refaat B. The fibrolytic potentials of vitamin $\mathrm{D}$ and thymoquinone remedial therapies: insights from liver fibrosis established by $\mathrm{CCl} 4$ in rats. $J$ Transl Med. 2016;14:281.

30. Palmai-Pallag T, Bachrati CZ. Inflammation-induced DNA damage and damage-induced inflammation: a vicious cycle. Microbes Infect. 2014;16(10):822-832.

31. Nakad R, Schumacher B. DNA damage response and immune defense: links and mechanisms. Front Genet. 2016;7:147.

32. Baird DD, Hill MC, Schectman JM, Hollis BW. Vitamin d and the risk of uterine fibroids. Epidemiology. 2013;24(3):447-453.

33. Paffoni A, Somigliana E, Vigano P, et al. Vitamin D status in women with uterine leiomyomas. J Clin Endocrinol Metab. 2013;98(8): E1374-E1378.

34. Halder SK, Laknaur A, Miller J, Layman LC, Diamond M, Al-Hendy A. Novel MED12 gene somatic mutations in women from the Southern United States with symptomatic uterine fibroids. Mol Genet Genomics. 2015;290(2):505-511.

35. Høyer-Hansen M, Bastholm L, Mathiasen IS, Elling F, Jäättelä M. Vitamin D analog EB1089 triggers dramatic lysosomal changes and Beclin 1-mediated autophagic cell death. Cell Death Differ. 2005; 12(10):1297-1309.

36. Demasters G, Di X, Newsham I, et al. Potentiation of radiation sensitivity in breast tumor cells by the vitamin D3 analogue, EB 1089, through promotion of autophagy and interference with proliferative recovery. Mol Cancer Ther. 2006;5(11):2786-2797.

37. Al-Hendy A, Diamond MP, El-Sohemy A, Halder SK. 1,25-dihydroxyvitamin D3 regulates expression of sex steroid receptors in human uterine fibroid cells. J Clin Endocrinol Metab. 2015;100(4):E572-E582.

38. Graziano S, Johnston R, Deng O, Zhang J, Gonzalo S. Vitamin D/ vitamin $\mathrm{D}$ receptor axis regulates DNA repair during oncogene-induced senescence. Oncogene. 2016;35(41):5362-5376.

39. Facciabene A, Motz GT, Coukos G. T-regulatory cells: key players in tumor immune escape and angiogenesis. Cancer Res. 2012;72(9): $2162-2171$

40. El Andaloussi A, Sonabend AM, Han Y, Lesniak MS. Stimulation of TLR9 with CpG ODN enhances apoptosis of glioma and prolongs the survival of mice with experimental brain tumors. Glia. 2006;54(6): 526-535.

41. Shevach EM. Mechanisms of foxp3+ T regulatory cell-mediated suppression. Immunity. 2009;30(5):636-645.

42. Schmidt A, Oberle N, Krammer PH. Molecular mechanisms of tregmediated T cell suppression. Front Immunol. 2012;3:51.

43. El Andaloussi A, Lesniak MS. An increase in CD4+CD25+FOXP3+ regulatory $\mathrm{T}$ cells in tumor-infiltrating lymphocytes of human glioblastoma multiforme. Neuro Oncol. 2006;8(3):234-243. 


\section{Supplementary material}

Table SI Sources for gene sequences and details of primer sequences used to amplify genes

\begin{tabular}{lllll}
\hline $\begin{array}{l}\text { Gene } \\
\text { name }\end{array}$ & Oligonucleotide primer sequences $\left(\mathbf{5}^{\prime}\right.$ to $\left.\mathbf{3}^{\prime}\right)$ & $\begin{array}{l}\text { PCR } \\
\text { product size }\end{array}$ & $\begin{array}{l}\text { Annealing } \\
\text { temperature }\left({ }^{\circ} \mathbf{C}\right)\end{array}$ & $\begin{array}{l}\text { Number of } \\
\text { PCR cycles }\end{array}$ \\
\hline TGF- $\beta$ & $\begin{array}{l}\text { F: CTTCGACGTGACAGACGCT; } \\
\text { R: GCAGGGGCAGTGTAAACTTATT }\end{array}$ & 210 & 60 & 40 \\
IL-10 & $\begin{array}{l}\text { F: GCTGGACAACATACTGCTAACC; } \\
\text { R: ATTTCCGATAAGGCTTGGCAA }\end{array}$ & 190 & 60 & 40 \\
$\beta$-actin & $\begin{array}{l}\text { F: CGTCATTGCACGAAGACACAA; } \\
\text { R: CCTGGTCCACCATTTTAAGGC }\end{array}$ & 220 & & \\
&
\end{tabular}

Abbreviations: PCR, polymerase chain reaction; $F$, forward; $R$, reverse.

\section{Publish your work in this journal}

The International Journal of Women's Health is an international, peerreviewed open-access journal publishing original research, reports, editorials, reviews and commentaries on all aspects of women's healthcare including gynecology, obstetrics, and breast cancer. The manuscript management system is completely online and includes a very quick and fair peer-review system, which is all easy to use. Visit http://www.dovepress.com/testimonials.php to read real quotes from published authors. 